\title{
Modelling of pedagogical technologies on the basis of activity approach
}

\author{
Volodymyr Steshenko ${ }^{1, *}$, Vladyslav Velychko ${ }^{1}$, Serhii Yashanov $^{2}$, Nadiya Vovk $^{1}$, and Olha Kitova ${ }^{3}$ \\ ${ }^{1}$ Donbas State Pedagogical University, 19 Henerala Batiuka Str., Sloviansk, 84122, Ukraine \\ ${ }^{2}$ National Pedagogical Dragomanov University, 9 Pyrohova Str., Kyiv, 01601, Ukraine \\ ${ }^{3}$ Donetsk Regional Institute of Postgraduate Pedagogical Education, 47 Vasylia Stusa Str., Kramatorsk, 84333, Ukraine
}

\begin{abstract}
The article identifies the main starting points for modelling pedagogical technologies based on the activity approach, namely: understanding of pedagogical technology as a scientifically sound activity aimed at forming the personality of the learner during the educational process by means of certain educational material; interpretation of pedagogical modelling as a process of creating such a reflection of the educational process that could reproduce a pedagogical object or process and replace it; the result of pedagogical modelling are images, forms of objects of pedagogical design. These are the relevant documents: concepts, state educational standards, curricula and programs, lesson plans, algorithms for action in lessons, diagrams, tables, etc.; drawing up a model of pedagogical technology based on the activity approach is an algorithm of actions, which includes: determining the subject of activity of the teacher and the student, selection of means of their activity, determination of conditions of pedagogical process, establishment of activity results. The generalized algorithm of drawing up of pedagogical technology model on the basis of the activity approach is presented by such steps: definition of a subject of activity for the teacher and the student separately; selection of means of their activity of the teacher; drawing up the process of educational activity of the teacher and the cognitive process of the student; determining the conditions for this process and establishing the results of this activity. The technology of creating a model for the implementation of interdisciplinary links based on the activity approach is represented by two stages: the creation of a model of their content and a model of the implementation process. The result of modelling the content of interdisciplinary links is to set goals for the use of knowledge from one subject in the study of another. The result of modelling the process of realization of interdisciplinary connections is the integral knowledge of the object of study formed in the student.
\end{abstract}

\section{Introduction}

At the present stage of development of pedagogical science a significant place in the organization and implementation of the educational process is given to pedagogical technologies. Pedagogical technologies have not become a completely new phenomenon in science. Previously, they were used in the form of principles, tools, conditions and even teaching methods. Examples include the development of problem-based or group learning, interdisciplinary connections, and so on. But in accordance with the achievements of pedagogical science, related to the integration of scientific knowledge, the involvement in pedagogy of knowledge from other scientific fields, scientists have managed to reach a new level of pedagogical development - technology development. Moreover, the compilation of technologies involved scientifically sound development of the organization of the educational process, ie design.

Design technology was proposed by J. Dewey [1]. The foundations of the design of educational technologies in Ukrainian pedagogy were laid by A. Makarenko [2], who sought to deprive the educational process (including its educational component) of spontaneity through the

*e-mail: steshenko.volodymyr@gmail.com use of thoughtful educational actions and their sequence. V. Sukhomlynsky paid great attention to pedagogical design, developed the ideas of A. Makarenko, emphasizing that the main area of connection of pedagogical theory and practice is human design as a result of skillfully constructed educational process [3], i.e, as a result of pedagogical technologies.

Today the work of many scientists is devoted to the problem of development of pedagogical technologies, models of their creation and use. In particular, in the work [4] noted that the success of pedagogical modelling depends on the existence of a theory that describes the phenomenon to be modelled, as well as the degree of formalization of the provisions of this theory.

The analysis of scientific and educational-methodical works of scientists shows that modelling of pedagogical technologies is presented by them on the basis of one of methodological approaches - system. But along with the systematic approach in pedagogical research, activity occupies a prominent place, because the educational process is one of the activities. Thus, modelling of pedagogical technologies should be considered not only on the basis of system, but also on the basis of activity approach. These circumstances led to the goal of this study. 
The purpose of the article is to reveal the essence of modelling pedagogical technologies on the basis of the activity approach. The research tasks:

1. To reveal the main starting points of modelling of pedagogical technologies on the basis of the activity approach.

2. To offer the generalized algorithm of modelling of pedagogical technologies on the basis of the activity approach.

3. Give an example of an algorithm for modelling one of the pedagogical technologies based on the activity approach - the technology of implementation of integrative learning (interdisciplinary links).

\section{Results}

First, we will focus on the initial methodological positions of modeling pedagogical technologies based on the activity approach.

The first position. In the scientific literature, pedagogical technology is considered by scientists in many ways and widely. Philosophers define technology as a form of motion of matter (technological form of motion of matter), as a progressive and human-controlled natural and social set of processes of purposeful change of various forms (mechanical, physical, chemical, biological, etc.), matter, energy and information flowing in systems of technology in accordance with these specific laws of structure and functioning [5].

Modern scientists give the following general definition of the science of technology: "technology is a science that studies the processes of transformation of some primary entities into entities that meet human needs while minimizing costs" [6]. M. Castells, one of the founders of the theory of the new sociology of the city, defined technology as "the use of scientific knowledge to determine ways of making things in a reproductive manner ..." [7].

Given the modern encyclopedic definition of "technology" should be understood as a field of human activity, the function of which is the development and theoretical systematization of objective knowledge about transformational activities, which contribute to the formation of scientific ideas about how to implement it.

Pedagogical technology is considered by scientists from different points of view [8-15]. We assume that since technology is interpreted as a scientifically sound activity to create a particular product, the pedagogical technology should be considered as a scientifically sound activity aimed at forming the personality of the learner by means of educational material. Moreover, the main thing in pedagogical technology, as scientists say, is the development and detailing of instrumental aspects of the pedagogical process.

I. Smolyuk and S. Smolyuk present pedagogical technology as "a project (model, system) of the educational process that determines the structure and content of educational and cognitive activities of students, their own vision of the need to become a high level professional". [16]. The essence of pedagogical technology is presented quite fully by M. Mykhailychenko and M. Rudyk. Scientists note that created and adapted to the needs and capabilities of the individual and society, pedagogical technology is a theoretically sound educational system of personal and professional development in an educational institution [17].

So, based on the fact that technology is a scientifically sound activity to create a certain product [5, 6, 18-25], and the educational process involves the comprehensive development of man as a person and the highest value of society, its talents, intellectual, creative and physical abilities, the formation of values and competencies necessary for successful self-realization [26], we understand pedagogical technology as a scientifically sound activity, aimed at forming the personality of students during the educational process by means of certain educational material.

The second position. The activity of determining adequate pedagogical solutions, the effectiveness of which has theoretical and practical confirmation, as well as their detailed, consistent and well-founded presentation is considered by scientists as a process of pedagogical design $[8,27-30]$. It is noted that pedagogical designing of activity of subjects of education is directed on construction of models of transformation of pedagogical reality, and essence of this process consists in revealing and the analysis of pedagogical problems and the reasons of their occurrence, revealing of value bases and construction of strategies of education, search for methods and means of their implementation, etc.

N. Morse considers two levels of pedagogical design [31]: the first as one of the functions of pedagogical activity (perspective planning of tasks and ways of their solution), the second as a separate type of activity having its own structure (diagnosing the object of design, conceptual modelling, project management system, stages project implementation, criteria for evaluating the success of the project). Pedagogical design is considered by scientists $[28,31,32]$ as a special kind of creative activity. Such activities include planning, programming, modelling, designing and predicting actions or consequences. Planning in the design process involves determining a set of activities for the relevant activities.

Programming involves determining the course of events in time and the order of the rules that must be followed to carry out the planned. Modelling - the creation of a system that is in objective accordance with the real object and which is able to replace it in a certain respect and gives the necessary information about the object itself. Design - the creation of a prototype of a certain object as a purposeful embodiment of innovative ideas, patterns of the educational process, principles based on knowledge of psychology, partial methods, pedagogical technologies and more. Forecasting is predicting the future state of an object or phenomenon based on the analysis of its past and present.

The result of pedagogical design is a set of documents, which includes a scientific justification of the design object in the form of a prototype of the pedagogical (educational) process. Such a prototype of the educational pro- 
cess is a model of projected technology. Thus, the main task in the design of pedagogical technology is to build a model of the educational process that could guarantee the teacher the effective achievement of goals. Thus, pedagogical modelling is the creation of a reflection of the educational process that could reproduce the pedagogical object or process and replace it so that new information can be obtained.

Third position. Since the purpose of designing pedagogical technology is to create a prototype of the educational process, the result of its construction is a model of this process, and modelling is one of the methods of pedagogical design.

In philosophy, the concept of "model" is defined as a representative or substitute for the original in cognition or in practice. Scientists note that the model is created to represent objects, phenomena or processes that do not yet exist in reality, or for some reason are not available. The model allows you to create images of these objects, phenomena or processes, to highlight some of their essential aspects, to simulate the real processes of future activities, to make an informed choice of one of the alternative solutions to problems, and so on. The model can take the form of a diagram, description, physical structures or formulas similar to the object (phenomenon) and reflects or reproduces in a simpler form the structure, properties and relationships between the elements of the object (phenomenon) [5, 8, 27, 33-39].

The model is considered by scientists as a means of cognition, and the creation of a model - modelling - by the method of scientific cognition [8, 27, 28, 32]. Modelling as a method of scientific cognition is a method of reproducing the characteristics of the object under study in an artificially created for its study reflection.

There are two types of models: substantive (material) and symbolic (figurative and formal). Formal ones, in turn, are divided into statistical, abstract-logical, and others. The structural elements of the abstract-logical model in pedagogy are the purpose, tasks, approaches and principles, stages of implementation, components, levels of formation, result and conditions of implementation. When modelling, all these elements are to be determined.

Pedagogical model is a mental system that mimics or reflects certain properties, features, characteristics of the educational process or the principles of its internal organization or functioning and is presented in the form of a certain form inherent in socio-cultural practice [8, 27, 28, 32]. That is, the pedagogical model is a reflection of the object of pedagogical design. According to the content, structure and functions of modelling objects, scientists [40] determine the semantic, structural and functional models. The semantic model reflects the content of the object of pedagogical design, the structural model reflects the structure and relationships between the components of the object, the functional reflects its functions. These models can be combined, for example, structural and functional in structural-functional.

The objects of pedagogical design include pedagogical systems, pedagogical process, pedagogical situations, as well as pedagogical technologies and educational environ- ment. In the works [32], [28] etc. objects of pedagogical design are presented as follows.

Pedagogical systems include such components as: teachers, students, material and technical subjects, processes, etc. According to their scale, scientists distinguish the following pedagogical systems: small (subsystems of educational institutions: educational, upbringing, methodical, etc.), medium (activities of the educational institution as a whole), large (education system of the city, district, region), ultra-large (education systems regions, republics, countries). They also define special pedagogical systems, which include the subjects of the educational process. The personality of the student is considered as a leading link in the pedagogical system.

The pedagogical process includes goals, objectives, content, methods, forms, tools that promote the development of students and teachers in their interaction. Its design involves combining these components into a single whole.

Another object of design is the pedagogical situation, which is part of the pedagogical process. The pedagogical situation characterizes the pedagogical process at a certain moment, which may arise by chance or be constructed specifically.

Pedagogical technologies reflect the sequence of actions of the teacher using different methods, forms and means of teaching or education.

The educational environment includes educational facilities, their equipment and design. The design of the educational environment involves the creation of new types.

The created model is a scientific result, "new knowledge obtained in the process of basic or applied research and recorded in the form of a report, scientific work, scientific report, scientific report on research work, monographic research, scientific discovery, etc." [41]. Therefore, images of pedagogical design objects should be considered as a result of pedagogical modelling. In this way, scientists identify forms of pedagogical design, which include the following documents: concepts, state educational standards, curricula and programs, comprehensive plans and work programs, lesson plans, algorithms for lessons, diagrams, tables, job descriptions, qualifications, etc. These forms are models of the corresponding objects.

Fourth position. In the scientific literature, human activity is defined as a process of active interaction of the subject with the object, in the process of which the subject meets its needs and achieves the goal [34, 42-44], i.e. expediently transforms, changes certain objects or subjects. As a result, we interpret the activity approach as a scheme of scientific knowledge, which is based on the consideration of the processes of transformation, change of certain objects (subjects). Since human activity is always appropriate and in some way organized, it is technological, functional (O. Rakitov) [45]. The structural components of such human activity in terms of general technology, we determine the subject of activity, means, process, organization (conditions) and the result of its implementation. Such structural components of activity were singled out by V. Davydov [42]. 
Activities that involve a certain movement, a consistent change of stages, a set of purposeful actions by scientists are interpreted as a process [14, 29, 42, 43, 46, 47]. Accordingly, the pedagogical process should be defined as activities aimed at achieving educational goals. It is known that teachers (provide training) and students (perform training) take part in the pedagogical process $[43,46]$. Thus, since the educational process is a purposeful, consistently organized interaction of teachers and students, mediated by the content of their joint activities, during which the tasks of education are solved [43, 46], then to design this activity, to develop a pedagogical model should be separately for the teacher and separately for the student. This approach ensures the implementation of the pedocentric approach in the educational process (J. Dewey [48] and others).

According to the general structural components of activity the subject of activity of the teacher is personal qualities of the applicant, and the subject of activity of the applicant - system of knowledge, the maintenance of training. The means of activity of the teacher are the means of pedagogical action: oral speech, visual aids, system of tasks, etc., and the means of activity of the student - textbooks and manuals, notebooks, computer, etc. The process of the teacher's activity is determined by the technology of organization of the cognitive activity of the student, and the process of the student's activity is determined by the stages of his cognitive activity. The conditions of the pedagogical process by the teacher are compliance with the requirements for its organization, taking into account the psychological and physiological characteristics of the student, knowledge of educational material and appropriate competencies, etc., and for the student it is the presence of motives for educational activities, teaching aids (textbooks, manuals, tasks, etc.) etc. The result of the teacher's activity and the result of the student's activity also differ: the result of the teacher's activity is the formed personal qualities of the student, the result of the student's activity is his education (preparedness), level of mastering competencies, level of culture in a certain educational field.

However, it should be emphasized that a clear definition of the subject, means, processes, conditions of organization and outcome for each subject of the pedagogical process separately makes it possible to more fully understand and define the features and clearly design its course.

Thus, given the above model of pedagogical technology based on the activity approach can be represented by the following algorithm:

1. Defining the subject of activity. For the teacher as a subject of activity personal qualities of each pupil act. For the student - a system of knowledge, methods of activity, values (competencies), etc. [43, 46].

2. Selection of means of activity. For the teacher as a means of activity are a variety of teaching aids, teaching methods and other supporting materials. For the student - means and methods of learning.

3. Drawing up the process of activity - building a methodology for the implementation of the educa- tional process (lesson or fragment of the lesson). For the teacher - this is a scientifically sound sequence of use of tools and application of methods and techniques for organizing the educational activities of the applicant. For the student - the stages of learning, mastering the methods of activity and the formation of personal qualities: perception, awareness, understanding, use and consolidation of educational material.

4. Determining the conditions of the pedagogical process. For the teacher - is the definition of circumstances that determine the organization and course of the process of forming personal qualities of each student (adherence to didactic and specific principles of the pedagogical process, structuring educational material, focus on the area of immediate development, etc.). For the learner - these are the circumstances that determine the organization of the process of cognitive activity - learning (attention, interest, motivation, etc.).

5. Establishment of results of activity. For the teacher, such results are formed certain personal qualities of the student. For the applicant - the level of education (preparedness) on certain issues (educational topics), the formation of his culture and so on.

As an example of creating a model of pedagogical technology based on the activity approach, we give the sequence of compiling the technology of implementation of integrative learning, which in modern pedagogy has not yet found a sufficiently complete development. The concept of integrative learning is used in several aspects, namely:

- as a term to define structures, strategies and activities aimed at combining general and profile subjects, academic disciplines and practical experience [49];

- as a process of developing the ability to learn, evaluate and make connections between significantly different concepts, areas of activity, or contexts [50];

- as a property that the student acquires during training and which consists in the ability to build simple connections between different ideas and experiences, the ability to combine and transfer learning experiences in new, complex situations that arise during and after training [51].

One of the cases of integrative learning is the realization of connections between academic disciplines (between subject connections). Interdisciplinary links are a reflection of integration processes in science [52], which is projected on the systematic and purposeful implementation of links between individual subjects [53].

Inert use of interdisciplinary connections is observed in the educational process. O. Globin identified objective and subjective causes of this condition: insufficient methodological basis; discrepancy in the time of studying related material in lessons in different subjects; different interpretations of concepts in different subjects; laborintensive and significant time spent in preparing teachers 
for interdisciplinary classes; inefficiency of one-sided use of interdisciplinary connections; lack of recommendations in the educational standard and programs for the implementation of interdisciplinary links. Subjective reasons include: weak motivation of school teachers to implement interdisciplinary links; insufficient theoretical and practical training of teachers to conduct classes using interdisciplinary links; practical lack of joint methodological associations of teachers [54].

In the holistic system of realization of interdisciplinary connections O. Globin identified the components: methodological, didactic, organizational-methodical, psychological-communicative, scientific-methodical.

The methodological component includes theoretical principles of interdisciplinary relations (their content and essence, types, classifications, functions, main components, methods of implementation, etc.), content and structure of related subjects, modern educational technologies [54].

The didactic component includes the goal; task; principles; substantive basis (general concepts, laws and theories); activity basis (general educational and cognitive skills); general research methods (observation, experiment, hypothesis and theory construction, modelling); means and methods of making interdisciplinary connections in educational classes; forms of organization of educational classes that promote the implementation of interdisciplinary links; system of tasks (including interdisciplinary) of applied (practical) content.

The organizational-methodical component includes the implementation of conceptual (substantive) and temporal coordination of the study of related subjects; ensuring continuity in the formation of understanding of general concepts, methods, study of laws and theories; application of general approaches to the formation of skills and abilities of educational work; disclosure of relationships between phenomena of different nature studied by related subjects; anticipation of difficulties and mistakes; defining a system of goals and objectives; plan educational work; planning of various forms of organization of educational and cognitive activities; organization of educational and cognitive activities depending on the purpose and tasks; organization and management of the subject groups and electives; formation of cognitive interest and motivation; mastery of methods of conducting complex (integrated) training sessions.

The psychological-communicative component includes the knowledge of psychological characteristics, individual needs of students, psychological foundations of communication, psychological and pedagogical conditions for the formation of knowledge and skills in individual subjects, as well as the ability to navigate in psychological situations, to establish interpersonal relationships.

The scientific-methodical component includes the ability to adapt new pedagogical technologies for the implementation of interdisciplinary links, to improve traditional methods of solving problems of interdisciplinary content; to organize self-educational work on mastering the system of interdisciplinary connections; analyse and summarize their own experience and implement the positive experience of colleagues in their implementation.

In view of the above and our own observations, we can draw such generalized but thorough conclusions. First: the inert use of interdisciplinary links by teachers in practice is due to their lack of understanding of the content and results of activities in the modelling and implementation of these links, ie the essence of the technology of implementation. Second: despite the fact that the implementation of interdisciplinary links in the educational process is an activity, in modelling the content and organization of cognitive activity of students for their implementation, methodologists and scientists do not use the structural components of the activity. Accordingly, the technology of implementation of interdisciplinary links requires refinement.

Thus, as we know, interdisciplinary connections are such relations of connection between educational subjects (disciplines), which determine the content of knowledge of students in some subjects by the content of knowledge from others, related ones. In our previous work [55] it is shown that the implementation of interdisciplinary links involves two stages. In the first stage, the teacher has to establish (plan) them, ie to determine probable models of the content of connections. In the second stage - to determine the model of organization of cognitive activity of students in the process of implementing interdisciplinary links. And the construction of a model of the content of interdisciplinary connections on the basis of the activity approach involves the definition of such characteristic features as the grounds, conditions of implementation and characteristics of the result of communication - the goals of knowledge transfer.

Yes, the subject of communication for subjects is the grounds for its existence. When modelling the content of interdisciplinary links as such a basis, it is necessary to identify common to related subjects objects, processes or methods of study.

The conditions for the existence of interdisciplinary links are the presence in each of the related subjects of the components of knowledge about the common object of study. Such components of knowledge are: scientific facts, concepts, laws and patterns, methods of cognition, and so on. Therefore, when modelling the content of interdisciplinary connections, it is necessary to determine the components of knowledge about the common object of study from the subject being studied and from related subjects with which the connection is established.

A means of modelling the content of interdisciplinary links is a table that includes three columns: the first column records the components of knowledge about the common object of study from the subject being studied. In the third - the components of knowledge about the common object of study in a related subject (subjects). And in the second - the purposes of transfer of knowledge from one subject to another are defined.

According to the third component of the activity approach, the process of activity is the process of drawing up a plan of interdisciplinary links, which includes the following stages: 


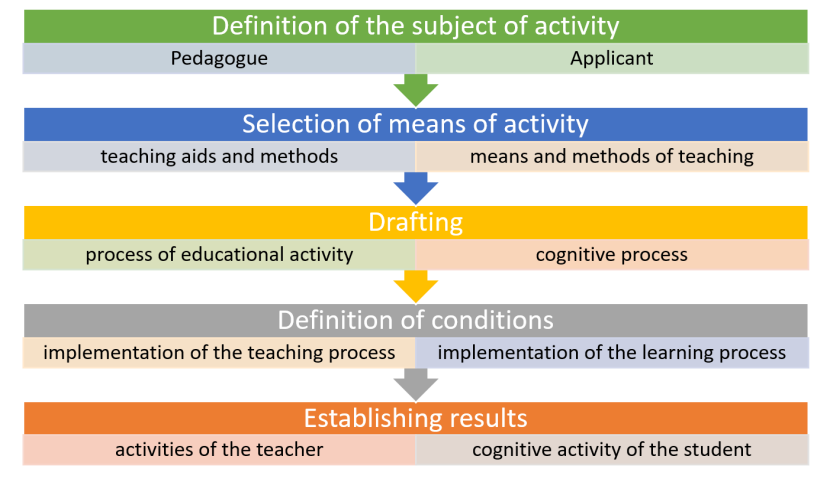

Figure 1. Algorithm for compiling a model of pedagogical technology based on the activity approach

1) identification and fixation in the table of a common subject for the studied subject and for a related subject of the object, process or method of study;

2) identification of the components of knowledge about the common object, process or method of study according to the curriculum of the studied subject and their fixation in the first column of the table;

3) identification of components of knowledge about a common object, process or method of studying the program of a related subject of the subject and fixing them in the third column.

The result of creating a model of interdisciplinary links is to determine the cognitive goals of transferring certain components of knowledge about a common object of study from one subject to another (such goals are: justification, generalization, specification, interpretation, illustration and combination (integration) of knowledge) and detection of duplication and violations of continuity between subjects, clarification and improvement of their content.

In [55] it is also shown that the process of realization of interdisciplinary connections involves the definition of stages and levels, didactic tools and techniques, conditions and results of their implementation (figure 1).

According to the activity approach, the first step of the algorithm for modeling the process of realization of interdisciplinary relations should be to determine the subject of interdisciplinary relations. Such a subject is the personal qualities of students, in particular the ability to think logically, transfer knowledge and more.

The second step is the selection of didactic means of making interdisciplinary connections, which can be: oral explanation; printed teaching aids (textbooks, reference books, manuals, posters, etc.); graphic tools (schemes of manifestation of laws and theories, structural-logical schemes, network schedules of curricula); interdisciplinary questions, problem and tasks (questions and tasks for substantiation, generalization, concretion, illustration, interpretation, integration of knowledge; technical tasks; complex tasks).

Third step is the construction of the content of the cognitive process for the implementation of interdisciplinary links, which includes the following stages: updating the knowledge of the learner in the basic (related) subjects (topics); updating of new knowledge by the teacher; setting tasks for the transfer of basic knowledge to new ones; solving problems on the transfer of knowledge of the student by the teacher or under the guidance of the teacher, or the student himself. The designer (teacher) must also determine the relevant knowledge of the learner in the basic (related) subjects (topics) for their actualization and new knowledge that he should offer on this subject; tasks for the student to transfer knowledge from related subjects to new studied ones; answers to these problems.

The fourth step of the algorithm is to determine the conditions for the implementation of interdisciplinary links, which are determined by the degree of independence of the student in performing educational tasks, the rules of joint activities of teacher and student and other circumstances that the teacher must provide. Depending on the degree of independence of the student to manage his cognitive activity for each case, the teacher must choose one of four levels: explanatory-illustrative, reproductive, partial-search or creative.

After that, according to the levels of independent activity of students should choose methods and techniques for organizing the cognitive activity of the student. According to the stages of interdisciplinary links, the following methods and techniques are:

- at the explanatory-illustrative level: reminders, statements, rhetorical questions, explanations;

- on the reproductive: asking questions or instructions on educational material in related subjects, teaching this material, asking questions and tasks to control the answers of students;

- in part-search: instructions or references to educational material in related subjects, presentation of this material by the teacher, teacher's instructions and control of tasks;

- on the creative - with the help of instructions and control of tasks.

The last step of the algorithm of the process of interdisciplinary connections is to determine the results of this process, which should be formed in the student's integrated idea of the object of study. That is, the student must demonstrate sound, generalized, concretized, integrated knowledge of the subject or illustrate them, as well as knowledge that can interpret the material studied in other subjects.

\section{Conclusions}

Thus, the main initial methodological positions in the modelling of pedagogical technologies based on the activity approach are:

- understanding of pedagogical technology as a scientifically sound activity aimed at forming the personality of the learner during the educational process by means of certain educational material; 
- interpretation of pedagogical modelling as a process of creating such a reflection of the educational process, which could reproduce the pedagogical object or process and replace it so that new information can be obtained;

- the result of pedagogical modelling are images, forms of objects of pedagogical design, which are the relevant documents: concepts, state educational standards, curricula and programs, comprehensive plans and work programs, lesson plans, algorithms for lessons, schemes, tables, job descriptions instructions, qualification characteristics, etc. These forms are models of the corresponding objects;

- modelling of pedagogical technology on the basis of activity approach is presented by algorithm of actions which includes definition of a subject of activity of the teacher and the pupil, selection of means of their activity, definition of realization conditions of pedagogical process, establishment of results of activity.

The technology of creating a model for the implementation of interdisciplinary links based on the activity approach includes the creation of a model of their content and a model of the implementation process. The result of modelling the content of interdisciplinary links is to set goals for the use of knowledge from one subject in the study of another. The result of modelling the process of realization of interdisciplinary connections is the integral knowledge of the object of study formed in the student.

The generalized algorithm for compiling a model of pedagogical technology based on the activity approach is represented by the following steps:

1. Defining the subject of activity for the teacher and the student separately.

2. Selection of activity means of the teacher (means and methods of teaching) and means of activity of the applicant (means and methods of teaching).

3. Drawing up the process of educational activity of the teacher and the cognitive process of the student.

4. Determining the conditions for the implementation of the learning process by the teacher and the learning process of the student.

5. Establishing the results of the teacher and the results of cognitive activity of the student.

Prospects for further research in this area are associated with the detailed development of models of basic pedagogical technologies based on the activity approach.

\section{References}

[1] J. Dewey, General Science Quarterly 1, 3 (1916)

[2] A. Makarenko, Soviet Studies in Literature 24, 70 (1988)

[3] V. Sukhomlinsky, Selected works, Vol. 4. Pavlysh secondary school. Conversation with a young school principal (Soviet School, Kiev, 1980)
[4] V. Volovich, ed., Sociology: a short encyclopedic dictionary (Kyiv, 1998)

[5] V. Kashirin, Philosophical issues of technology (sociological, methodological and technological aspects) (Tomsk, 1988)

[6] G. Nazarenko, G. Osipov, Fundamentals of the theory of medical technological processes, Vol. 1 (FIZMATLIT, Moscow, 2005)

[7] M. Castells, The information age (Oxford Blackwell Publishers, 1996)

[8] N. Brukhanova, Fundamentals of pedagogical design in engineering and pedagogical education (NTMT, Kharkiv, 2010)

[9] I. Dychkivska, Innovative pedagogical technologies (Akademvydav, Kyiv, 2012)

[10] O. Pekhota, A. Kiktenko, O. Lyubarska, Educational technologies (ASK, Kyiv, 2001)

[11] G. Selevko, Encyclopedia of educational technologies (Moscow, 2006)

[12] N. Bordovskaya, ed., Modern educational technologies (KNORUS, Moscow, 2011)

[13] V. Steshenko, Pedagogical design in technological education (DDPU, Sloviansk, 2018)

[14] V. Strelnikov, I. Britchenko, Modern technologies of higher education: a modular manual for students of author's refresher courses for teachers of MIPK PUET (PUET, Poltava, 2013)

[15] M. Chepil, N. Dudnyk, Pedagogical technologies (Akademvydav, Kyiv, 2012)

[16] I. Smolyuk, S. Smolyuk, Scientific Bulletin of Volyn National University named after Lesya Ukrainka. Section IV. Professional education 8, 108 (2012)

[17] M. Mikhailichenko, M. Rudyk, Educational technologies (COMPRINT, Kyiv, 2016)

[18] V. Gorokhov, Epistemology and philosophy of science XXVIII, 110 (2011)

[19] A. Mironov, Philosophy of science, technology and technology (MAX-Press, Moscow, 2014)

[20] V. Sidorenko, Labor training in educational institutions 2, 3 (2011)

[21] Technology published by the main department of schools (in St. Petersburg by the Imperial Academy of Sciences) (St. Petersburg, 1807)

[22] Dictionary of the Ukrainian language, Vol. 10 (: Naukova Dumka, Kyiv, 1980)

[23] A. Abdula, H. Baluta, N. Kozachenko, D. Kassim, CEUR Workshop Proceedings 2643, 306 (2020)

[24] J. Salomon, History of technology 1, 113 (1984)

[25] S.O. Semerikov, I.O. Teplytskyi, V.N. Soloviev, V.A. Hamaniuk, N.S. Ponomareva, O.H. Kolgatin, L.S. Kolgatina, T.V. Byelyavtseva, S.M. Amelina, R.O. Tarasenko, Journal of Physics: Conference Series 1840, 012036 (2021)

[26] Law of Ukraine 'On Education' (2017), https:// zakon.rada.gov.ua/laws/show/2145-19

[27] V. Bezrukova, Pedagogy. Projective pedagogy (Delovaya kniga, Ekaterinburg, 1996) 
[28] I. Kolesnikova, M. Gorchakova-Sibirskaya, Pedagogical design (Academy, Moscow, 2005)

[29] I. Konovalchuk, Zhytomyr Ivan Franko State University Journal 5, 71 (2005)

[30] N. Moreva, Technologies of professional education (Academy, Moscow, 2008)

[31] N. Morze, Methods of teaching informatics, Vol. I: General methods of teaching informatics (Kyiv, 2004)

[32] L. Gorbunov, Practical pedagogy (Izd-vo Vost.-Sib. state acad. education, Irkutsk, 2012)

[33] V. Shinkaruk, ed., Philosophical encyclopedic dictionary (Hryhoriy Skovoroda Institute of Philosophy of the National Academy of Sciences of Ukraine, Kyiv, 2002)

[34] D. Levites, Autodidactics. Theory and practice of designing own learning technologies (Moscow Psychological and Social Institute Publishing House, MODEK Publishing House, Moscow, Voronezh, 2003)

[35] Y. Modlo, S. Semerikov, P. Nechypurenko, S. Bondarevskyi, O. Bondarevska, S. Tolmachev, CEUR Workshop Proceedings 2433, 413 (2019)

[36] V. Soloviev, N. Moiseienko, O. Tarasova, CEUR Workshop Proceedings 2393, 905 (2019)

[37] O. Korotun, T. Vakaliuk, V. Soloviev, CEUR Workshop Proceedings 2643, 281 (2020)

[38] O. Kravchenko, I. Borisyuk, Z. Vakolia, O. Tretyak, O. Mishchenia, International Journal of Higher Education 9, 94 (2020)

[39] I. Lovianova, K. Vlasenko, I. Sitak, I. Akulenko, O. Kondratyeva, Universal Journal of Educational Research 8, 3883 (2020)

[40] Y. Lodatko, Higher education in Ukraine pp. 68-72 (2013)
[41] V. Busel, ed., Large explanatory dictionary of the modern Ukrainian language (Perun, Kyiv, Irpin, 2001)

[42] V. Davydov, S. Kerr, Educational Researcher 24, 12 (1995)

[43] V. Yagupov, Pedagogy (Lybid, Kyiv, 2003)

[44] P. Nechypurenko, O. Evangelist, T. Selivanova, Y. Modlo, CEUR Workshop Proceedings 2732, 984 (2020)

[45] A. Rakitov, Philosophy of the computer revolution (Politizdat, Moscow, 1991)

[46] N. Moisenyuk, Pedagogy (KDNK, Kyiv, 2001)

[47] S. Sysoeva, L. Bondareva, Pedagogical technologies of professional training (University 'Ukraine', Kyiv, 2007)

[48] J. Dewey, Psychological Review 1, 63 (1894)

[49] T. Rhodes, Assessing Outcomes and Improving Achievement: Tips and Tools for Using Rubrics (Association of American Colleges and Universities, Washington, DC, 2010)

[50] M. Huber, P. Hutchings, Integrative Learning: Mapping the Terrain (Association of American Colleges and Universities, Washington, DC, 2004)

[51] J. Klein, Peer Review 7, 8 (2005)

[52] N. Rashevska, V. Soloviev, CEUR Workshop Proceedings 2257, 192 (2018)

[53] I. Kholoshyn, O. Bondarenko, O. Hanchuk, E. Shmeltser, CEUR Workshop Proceedings 2433, 403 (2019)

[54] O. Globin, Interdisciplinary links in the context of specialized teaching of mathematics: a guide for teachers (Pedagogical Thought, Kyiv, 2012)

[55] V. Steshenko, D. Thorzhevsky, School and production 11, 75 (1989) 